\title{
La Guerra Civil española en la literatura juvenil del siglo XXI: pacifismo y pluralidad
}

\author{
Begoña Regueiro Salgado ${ }^{1}$; Pilar García Carcedo²
}

Resumen. La literatura histórica se convierte en un puente tendido entre la comprensión del pasado y la mejora del futuro. La primera pregunta de investigación debería ser si los efectos de la Guerra Civil están todavía presentes en la sociedad española y en nuestra literatura infantil y juvenil. En estas páginas, se demostrará que los diferentes episodios de la Guerra Civil (la pre-guerra, la guerra y la postguerra) reaparecen con frecuencia en los libros históricos para jóvenes. Se ha llevado a cabo un análisis detallado de algunas de las novelas más representativas escritas entre los años 2000 y 2020 en las distintas lenguas oficiales españolas para descubrir qué tipo de ideas sobre la guerra se están transmitiendo a los jóvenes en esa literatura juvenil.

Palabras clave: Memoria histórica. Guerra civil española. Literatura infantil y juvenil. Pacifismo. Pluralidad.

[en] Tristes armas. Civil War in Spanish Children's Literature of XXI Century: Pacifism and Plurality

Abstract. Historical literature becomes a bridge between the understanding of the past and the improvement of the future. First research question should be whether Spanish Civil War's effects are still present in our society and in our children's and youth literature or not. In these pages, it will be shown that different episodes of Civil War (pre-War, War and Post- War) appear frequently in historical books for young people. A close reading of some representative books written between 2000-2020 in the different official languages of Spain has been carried out to discover which kind of ideas about war are being given to young people in youth literature.

Keywords: Historical memory. Spanish Civil War. Children's and Youth Literature. Pacifism. Plurality

[fr] Tristes armas. La Guerre civile dans la littérature espagnole pour la jeunesse du XXIe siècle: pacifisme et pluralité

Résumé. La littérature historique devient un pont entre la compréhension du passé et l'amélioration de l'avenir. La première question de recherche devrait être de savoir si les effets de la guerre civile espagnole sont toujours présents dans notre société et dans la littérature pour enfants et adolescents. Dans ces pages, il sera montré que les différentes épisodes de la Guerre Civile (avant-guerre, guerre et après-guerre) réapparaissent fréquemment dans les livres historiques pour la jeunesse. Une analyse détaillée de certains des romans les plus représentatifs écrits entre les années 2000 et 2020, dans les différentes langues officielles espagnoles, a été effectuée pour découvrir quel genre d'idées sur la guerre sont transmises aux jeunes dans cette littérature.

Mots-clés: Mémoire historique. Guerre civile espagnole. Littérature jeunesse. Pacifisme. Pluralité.

Sumario: 1. Introducción. 2. Análisis de obras. 3. Conclusiones. 4. Bibliografía.

Cómo citar: Regueiro Salgado, Begoña; García Carcedo, Pilar (2020): "La Guerra Civil en la literatura juvenil del siglo XXI: pacifismo y pluralidad", en Didáctica. Lengua y Literatura, 32, 195-205.

Departamento de Didáctica de las Lenguas, las Artes y la Educación Física, Universidad Complutense de Madrid bregueir@ucm.es

2 Departamento de Didáctica de las Lenguas, las Artes y la Educación Física, Universidad Complutense de Madrid pcarcedo@ucm.es 


\section{INTRODUCCIÓN}

Es necesario conocer la historia para no cometer los mismos errores. Se trata de una frase repetida hasta la saciedad, pero no por ello es menos cierta. Hay muchas formas de acceder a la historia y, probablemente, cada persona o cada circunstancia requiera una; sin embargo, parece que la novela histórica o de ambientación histórica ${ }^{3}$ tiene un valor especial en la medida en la que nos puede acercar a episodios menos conocidos y, sobre todo, nos aproxima a lo que Unamuno, en En torno al casticismo, llamó intrahistoria, es decir, las pequeñas historias, lo que subyace y ocurre por debajo de las grandes batallas o las grandes fechas.

Por otro lado, Teresa Colomer (2009), y casi todos los que se han aproximado al tema, han destacado el papel socializador de la Literatura Infantil y Juvenil ${ }^{4}$ y la importancia de esta en la transmisión de los valores que imperan en una sociedad determinada. La literatura en general suele contribuir a la transmisión ideológica, y, como afirma Orquín "tiene un extraordinario poder de sugestión y todo gran lector sabe en qué medida los personajes de ficción han conformado su propia vida, su manera de sentir y de pensar" $(1989,15)$. Pero, en el caso de la literatura infantil y juvenil, la influencia ideológica es todavía más evidente, como mantiene también Etxaniz Erle (2004) en su estudio.

Así, pues, la novela juvenil de tema histórico o de ambientación histórica desarrolla un papel fundamental en la imagen del pasado que queremos transmitir a las nuevas generaciones. Tal vez por ello, es un tema que nunca ha dejado de aparecer en la narrativa destinada a los más jóvenes. Fue un tema fundamental durante todo el siglo XX y lo sigue siendo en el siglo XXI. En el estudio Historia crítica de la Literatura Infantil y Juvenil en la España actual (1939-2015), en el capítulo de "Una narrativa infantil y juvenil para el nuevo siglo (1990-2015)", Jaime García Padrino dedica un apartado específico a "La recuperación del pasado histórico", y comienza señalando que "los temas y ambientaciones de carácter histórico mantuvieron durante estos años la vigencia conseguida en los años anteriores" $(2018,574)$. A partir de aquí, el crítico realiza un recorrido por la literatura infantil y juvenil escrita en lenguas peninsulares para probar la proliferación de este tipo de obras y, en efecto, lo consigue. Si revisamos los títulos que ofrece, podemos ver que las narraciones abarcan todos los periodos históricos: desde la Prehistoria, las civilizaciones antiguas, la Edad Media, los Siglos de Oro, el siglo de las Luces, el convulso siglo XIX y, por supuesto, el siglo XX. Hasta cierto punto, es normal que la novelística destinada a los más jóvenes ofrezca este tipo de títulos, puesto que, en muchas ocasiones, el mundo editorial, uno de los grandes mediadores literarios, se alía con el otro gran mediador, la escuela, y en su selección de obras sigue un criterio "que tiene que ver más con los valores o con la adaptación a una competencia lingüística o cultural del niño [...] que con la literariedad de la propuesta" (Lluch, 2010, 108). Así, de acuerdo con los contenidos curriculares, muchas de estas obras buscan apoyar y reforzar los contenidos que se imparten en la escuela. Sobre la pertinencia o no de esta instrumentalización de la literatura podríamos debatir durante páginas y páginas, pero lo que nos interesa ahora es que, dentro de esta ingente cantidad de obras históricas, las destinadas al siglo XX se han multiplicado y, si la Edad Media contaba con más de treinta títulos, en este caso, encontramos más de cuarenta. Del siglo XX interesan muchos episodios, tanto de la historia española, (la pérdida de las colonias, que se considera el inicio del siglo XX, la Guerra de África etc.), como de la historia internacional (la Revolución Mexicana, la Segunda Guerra Mundial). Sin embargo, el tema por excelencia es, sin duda, la Guerra Civil española, probablemente por la vigencia que todavía tiene en la conformación de la sociedad de la España del siglo XXI. A este respecto, Olaziregui afirma:

la verdad es que el debate en torno a las causas y consecuencias de la Guerra Civil tiene una actualidad absoluta dentro de la sociedad española. Baste recordar, por ejemplo, que el pasado 26 de diciembre se aprobó la [...] Ley de la Memoria Histórica (Olaziregui, 2008, 15)

Y, si esto se podía decir en 2008, ¿qué no podremos decir en 2020 cuando uno de los temas que marcaron las elecciones, varias veces repetidas, de 2019 fue la exhumación de Francisco Franco, aprobada en medio de la polémica, por el Gobierno de Pedro Sánchez el 15 de febrero de 2019 y llevada a cabo, tras varias suspensiones, el 24 de octubre de 2019? En un momento en el que los grupos políticos de ideologías más radicales cobran protagonismo, la Guerra Civil resurge como tema en la LIJ.

Como también señala Olaziregui, el tema había sido tratado profusamente por la literatura adulta, pero en la joven ha tardado más, tal vez por ser temas arduos para los lectores más jóvenes, o, como señala Valriu, tal vez por haber necesitado que se asentase la democracia y se cerrasen algunos procesos:

Val a dir que- atès el posicinament ideológic dels autors- es comprensible que aquestes obres no es publiquin fins vint anys després de la fi de la dictadura, porqué la transició del páis cap a la democràcia i el reconeixement de les nacinalitats ha estat en un camí lent i no exempt d'entrebancs (Valriu, 2014, 317).

\footnotetext{
Según Valriu (2013: 310), la diferencia entre ambas radica en que la narración histórica gira en torno a la historia y el eje de su temática es la historia, mientras que la narración de ambientación histórica trata otros temas, como el misterio, el crecimiento personal, los sentimientos etc. y la ambientación histórica desarrolla un papel secundario, meramente contextual.

4 A partir de ahora LIJ.
} 
Con esta idea coincide Roig cuando señala que la Guerra Civil no fue abordada por los escritores del marco ibérico debido a un contexto sociopolítico y cultural "que implicaba un férreo control da temática que se trataba nas obras literarias dirixidas aos máis novos e mesmo a existencia de moitos temas tabú" (Roig, 2008, 71).

Por su parte, Nieves Martín Rogero (2008) considera que la entrada en la LIJ de los años ochenta y noventa de nuevos temas que incluyen la marginación, la violencia o nuevos modelos sociales, facilita la inclusión del tema de la guerra y su repercusión en los más jóvenes en novelas "que despuntan por su calidad y transmiten un deseo de denuncia antes amordazado" (Martín Rogero, 2008, 49).

En cualquier caso, cuando la Guerra Civil española llega a la LIJ, lo hace con fuerza y así lo han atestiguado los estudios de Gräfin (2007), con referencia a más de ochenta títulos, Roig Rechou (2011), y Agra Pardiñas y Roig Rechou (2004), que extienden el análisis a las otras lenguas peninsulares y más allá de las fronteras españolas. Igualmente, desde una perspectiva didáctica, Pérez Reverte ha publicado en 2015 La Guerra Civil contada a los jóvenes, obra de conjunto que presenta numerosas anécdotas de guerra, pero a la que se le achaca no haberse aproximado suficientemente a las causas del conflicto. Además de los estudios citados, Valriu enumera algunas de las obras que han analizado desde un punto de vista crítico la presencia de la Guerra Civil en la LIJ y afirma que es reducido. Entre ellas destaca el artículo de Joan Portell (2001) o los estudios de obras concretas como el realizado por M. Dorisol en 2001. Por otro lado, aunque no se refieran solo al conflicto español, la autora señala algunas obras que se relacionan con este tema al hablar de las guerras como "inspiración creativa para la literatura infantil y juvenil" y, entre otras, menciona: Mundos en conflicto: Representación de ideologías, enfrentamientos sociales y guerras en la Literatura Infantil y Juvenil, dirigido por V. Ruzicka Kenfel y otras (2005), y el ya citado A memoria das guerras na Literatura infantil e xuvenil en lingua galega. As súas repercusións na infancia e adolescencia, editado por Agra Pardiñas y Roig Rechou en 2004. Habría que añadir, por último, el propio volumen en el que publica la autora, A Guerra Civil Española na narrativa infantil e xuvenil, coordinado por Ana-Blanca Roig Rechou, Pedro Lucas Domínguez e Isabel Soto López, en 2008 y los diversos artículos a los que hacemos mención en este estudio. Por último, Guido Planes en su estudio sobre la presencia de la Guerra Civil en el álbum ilustrado, habla de tres selecciones de obras publicadas por tres entidades dedicadas a la divulgación de la LIJ: La Guerra en la literatura para niños y para jóvenes, de la Fundación Germán Sánchez Ruipérez; Il-lustrar u escriuire la Guerra Civil, del Servei de Documentació de Literatura Infantil i Juvenil de Barcelona; y Libres de literatura infantil i juvenil de coneixements que tracten de la guerra i la pau, del CPR Sarriá- San Gervasi de Barcelona (Guido Planes, 2011, 33).

En efecto, la bibliografía no es excesivamente extensa, pero tampoco parece ya tan escasa. Llama la atención, no obstante, la distinción permanente que se hace en los estudios según las autonomías llamadas históricas a las que pertenezcan tanto el investigador como el autor de la obra. Entra dentro de lo esperable que, además de los estudios más generales que se centren en las obras publicadas en toda España, existan estudios específicos para las obras escritas en gallego, euskera o catalán, pero es curioso que, en este caso, sean casi más prolijos los estudios sobre la situación en las literaturas gallega, vasca o catalana que los que tratan de dar una visión de conjunto. Tenemos profundos análisis de la clasificación o las características de la LIJ que trata la Guerra Civil en las literaturas regionales, pero ¿existe semejanza entre ellas? ¿comparten características o periodización? En eso trataremos de centrarnos, pero también en otro aspecto que se deja ver en este hecho ¿se ha convertido la literatura de temática de la Guerra Civil en una de las herramientas para reivindicar el nacionalismo y educar en los valores nacionalistas a los adolescentes y jóvenes que las leen? Parece que el testimonio de Valriu así lo avala cuando incluye las obras sobre la Guerra Civil entre las obras para estudiar historia catalana en la escuela y cuando ella misma se plantea

podem dir que és innegable que les novel·les que comentem pretenen crear uns referents històrics que tipifiquin unes aspiracions comunes encaminades a fer país, a construir el sentiment de pertinença i d'identitat nacional del lector (Valriu, 316).

Lo mismo podría decirse de las obras vascas, como la que analizaremos de Miren Agur, o La batalla de Matxitxaco (2002), de Fernando Marías, entre cuyos temas Nieves Martín destaca el nacionalismo vasco (46). Parece que un hecho tan crucial como la Guerra Civil Española fue vista y es reflejada en la literatura para los más jóvenes de maneras muy diversas. Es este un punto que nos interesa estudiar, pero también es fundamental tener en cuenta que, dentro de esta múltiple perspectiva del mismo hecho, también existe un elemento común: el pacifismo, el antibelicismo y el antimilitarismo. Por eso, ese será el otro tema en el que nos centraremos de manera especial en este estudio.

Antes de pasar a estos temas, es importante revisar las clasificaciones que ha hecho la crítica para comprobar si, como decíamos antes, lo que se ha analizado de manera local, se puede extrapolar para hablar de características generales.

Para empezar, podemos señalar los rasgos que atribuye Valriu a las obras catalanas que hablan de la guerra. La estudiosa señala varios aspectos: presencia de fechas relevantes, yuxtaposición del presente y el pasado, atención a la trayectoria vital del protagonista, que siempre es un personaje positivo (frente a un tratamiento poco elaborado y más plano de los personajes negativos, cuya presencia es secundaria y, a veces, anecdótica) (Valriu, 312 et. sic). Así mismo, como elemento común a la treintena de obras analizadas, Valriu señala una serie de dicotomías que vendrían a establecer la ideología que se defiende: legitimidad vs ilegitimidad (República vs alzamiento militar); democracia vs dictadura; pluralidad nacional vs españolismo; libertad religiosa vs nacionalcatolicismo; feminismo vs machismo; educación vs 
incultura (la República educaría mientras que la Dictadura adoctrinaría) (Valrius, 317). De este modo la ideología se podría definir con cinco adjetivos "republicana, catalanista, feminista, antibellicista i d'esquerres" (Valrius, 317). ¿Existe alguna diferencia con las obras escritas en castellano, gallego o vasco? A primera vista, no. Ni siquiera podemos decir que el nacionalismo catalán sea exclusivo, pues lo que es catalanismo en estas obras, es galleguismo o vasquismo en las escritas en estas lenguas, por lo que si sustituimos la palabra "catalanismo" por "nacionalismos" se convierte en una característica general de las obras de LIJ sobre la Guerra Civil española, con la excepción de las que se han escrito en castellano. En cuanto a la yuxtaposición de tiempo, etc. la misma Valriu establece una serie de posibles estructuras que se repiten y que no siempre implican la yuxtaposición, sino que también incluyen la narración en tercera persona, el diálogo intergeneracional, la narración en primera persona, la novela a través de diarios o cartas, etc. (312-313).

Por su parte, Roig, cuando habla de la LIJ gallega establece cuatro tipologías: la literatura testimonial (memorias, crónicas, epistolarios, autobiografías), en las que un protagonista infantil habla de la vida social y familiar en el tiempo al que alude; "sombras e descubertas da Guerra Civil" (174), en las que incluye narraciones de tipo iniciático, pero también elementos de misterio, terror, etc. en los que son los adolescentes los que deben encontrar la respuesta; "ruptura de traxectorias vitais e aprendizaxes á forza" (85), en las que incluye obras de iniciación protagonizadas por los "niños y niñas de la guerra" que fueron separados de sus familias; y por último, "a Guerra Civil lembrada, referida ou aludida a partir de narradores adultos" (89), en las que "describo obras de carácter moi heteroxéneo na que os seus respectivos narradores dan conta da situación de Galicia e dos galegos como consecuencia da Guerra" (89). Al analizar estas características que define Roig salta a la vista, de nuevo, que, salvo la preocupación por Galicia (que entraría dentro del nacionalismo o regionalismo ya mencionado) todo lo demás son rasgos extrapolables a toda la literatura sobre la Guerra Civil, porque, además, todo lo que tiene que ver con la novela de aprendizaje es común denominador de la LIJ, donde personajes adolescentes deben llevar a cabo un camino de conocimiento personal. Lo mismo ocurriría con las temáticas relacionadas con el misterio, lo policíaco e, incluso, lo sentimental, pues son elementos que suelen aparecer en las obras juveniles como reclamo para el lector o lectora. Junto a estos rasgos, que se mezclan con una temática bélica, las características principales de la literatura infantil y juvenil aparecen en la forma en que se cuentan las historias. Según Marcelo (2007, 19 et.sic) su peculiaridad parte de conseguir un lenguaje sencillo y repetitivo, con personajes infantiles o juveniles de clara adscripción moral (buenos o malos) y un cierto contenido didáctico que transmite experiencias y valores a los lectores jóvenes.

Por último, antes de pasar al análisis de las obras, cabe precisar que, cuando hablamos de la época de la Guerra Civil, no nos ceñimos a los tres años que duró la contienda estrictamente, sino que ampliamos el abanico de tiempo. En este sentido, Valriu habla de tres momentos: las novelas que se sitúan en los tiempos históricos de la guerra (19361939); las novelas que se sitúan en la posguerra (1940-1960); y las novelas que se sitúan en un tiempo más próximo, es decir, los últimos años del franquismo y el periodo de transición (313).

En nuestro caso, la división sería entre los últimos años de la II República y el estallido de la Revolución o Alzamiento); los años de la guerra (1936-1939); y la posguerra, donde habría que distinguir por la entidad que cada una de ellas tiene, las obras que hablan del exilio y las que hablan de la posguerra vivida en España, donde tienen un peso especial las obras en las que se hace referencia a los maquis.

Dicho esto, podemos señalar que, dentro de los textos que tratan el tema de la Guerra Civil Española, hay obras que se han convertido ya en clásicos de la LIJ como Memorias de una vaca (1992, SM) de Bernardo Atxaga. Sin embargo, en este artículo, vamos a profundizar en novelas más recientes, algo menos conocidas y, sobre todo, menos estudiadas. Además, intentaremos que sean representativas de la literatura española en general, entendiendo que para ello, es necesario contar con obras escritas en castellano, en gallego, en euskera y en catalán. Por último, señalamos que, en el análisis que hagamos de ellas, trataremos de prestar especial atención a los rasgos que hemos descubierto como característicos de todas las obras: el pacifismo o antibelicismo y la presencia de los nacionalismos.

\section{ANÁLISIS DE OBRAS}

\subsection{Cielo abajo de Fernando Marías (2005, Madrid, Anaya)}

Para un análisis detallado de uno de los textos que tienen como tema central la Guerra Civil española, se ha elegido la obra Cielo abajo (2005, Madrid, Anaya), de Fernando Marías, que recibió el Premio Nacional de Literatura Infantil y Juvenil en 2006. La novela se centra en la batalla de Madrid en 1936, pero presenta el contrapunto del escritor que encuentra la historia en la capital en la actualidad del siglo XXI. Además, la temática bélica se completa con una tierna historia de amor platónico adolescente, siempre en ese contexto de guerra. Narra la historia de Joaquín Dechén, un huérfano adolescente que siempre ha soñado con ser aviador y termina consiguiéndolo en los aviones del bando nacional franquista.

Precisamente, el mayor interés de esta obra es que presenta una perspectiva abarcadora, ya que la infancia del protagonista se forma rodeada de todos los valores y creencias del bando franquista, mientras que, más adelante, se tiene que infiltrar en el Madrid republicano, en la casa de Constanza, de la que se enamora platónicamente, y empieza a escuchar por primera vez la perspectiva del otro bando. Se observan claramente las contradicciones, las formas manipuladoras de observar la realidad, como lo resume muy bien al final el propio protagonista: 
¡Qué extraña mi guerra doble! Dentro de Madrid, los héroes eran los milicianos y los brigadistas; fuera, se hablaba del arrojo de los soldados moros, de los riesgos que asumían los eficaces aviadores nazis. Y los únicos que parecían tener razón eran los caídos de uno y otro bando, imperturbables, callados, muertos $(2005,161)$.

Al principio, sin embargo, la ideología es claramente la del bando nacional, como se puede observar en este otro fragmento en el que se narra el comienzo del alzamiento con el golpe de estado del 18 de julio de 1936:

Observé, desconcertado, que la bandera no tenía los colores de siempre. Ahora era roja y amarilla, sin la franja morada.

-iSoldados!- gritó el coronel, tras desenfundar su pistola-. Hace unas horas, nuestro glorioso ejército se ha levantado en armas contra la República y sus corruptos gobernantes. ¡Ha llegado la hora de salvar a España! ¡Gritad conmigo! ¡Viva España! (cit. 29)

Queda muy patente, en la primera parte de esta novela, hasta qué punto el aleccionamiento de los jóvenes podía ser enormemente marcado en este período de guerra, dependiendo de la zona de España en que les hubiera tocado vivir. Porque, como decía el poeta Machado, "una de las dos Españas ha de helarte el corazón”; versos que, aunque no se refirieran exactamente al conflicto, nos sirven para rememorar la bipolaridad que se instauró en la geografía española. En esta novela se nos ofrece la historia, por lo tanto, desde las dos perspectivas, completando el dramático puzle de la intolerancia. Por un lado, se ofrecen referencias también a la matanza del Cuartel de la Montaña, para ilustrar que las terribles actuaciones se produjeron también en el bando de los republicanos. Por otro lado, el comienzo de la novela se enfoca desde la admiración al general golpista Francisco Franco: "El general más joven de Europa. Un gran soldado. ¡Hermano del aviador del Plus Ultra!... La música militar y los ¡vivas! a Franco que se gritaron incansablemente aquel día se me antojaban dirigidos a mí y a mi futuro" (59). Pero, más adelante, el protagonista irá conociendo también la perspectiva republicana.

A continuación, le piden al joven Joaquín que se infiltre en Madrid, que resiste a los invasores, para pasar informaciones del alto mando republicano. Siempre desde la perspectiva de los autores del alzamiento, de Madrid se dice que "en la capital no manda nadie, excepto el caos y, si acaso, los agentes de Stalin" (64); o, más claro el aleccionamiento, que "Madrid se hallaba en manos de pistoleros y asesinos, bandidos sin ley ni moral que se llamaban a sí mismos revolucionarios... Si me descubrían podían fusilarme" (68).

Pero, en cuanto el joven huérfano llega a la capital, descubre también los horrores de los bombardeos nacionales sobre la población civil. Así, cuando una joven cae muerta en los brazos del protagonista: "Todo el mundo gritaba, enloquecido por las siguientes explosiones. Pero la chica que me había gustado callaba en mis brazos... Callaba y no respiraba" (70).

\subsection{Noche de alacranes, Alfredo Gómez Cerdá (2005)}

Esta obra de Alfredo Gómez Cerdá, escrita en 2005, recibió en ese mismo año el Premio Gran Angular y lleva ya nada menos que doce reediciones. Tal vez su principal logro es la perspectiva femenina de la joven protagonista, Catalina, también llamada Delgadina, y la maravillosa historia de su amor hacia Emilio Villarente que entrevera sus páginas. Desde el primer momento se trata de un amor imposible que recuerda al lector a los inmortales Romeo y Julieta, porque los dos protagonistas, que se conocen en un baile del pueblo, desgraciadamente parecen pertenecer a bandos opuestos, por lo que el hermano de ella advierte de que se trata de una relación prohibida: "-No vuelvas a acercarte a ese-le dijo de pronto - ¿Y por qué no puedo acercarme a ese? -No es de los nuestros... A lo mejor en otro lugar y en otra época no sería malo, pero aquí y ahora sí que lo es" (G. Cerdá, 2017, 40). La protagonista recuerda su amor juvenil desde la vejez, cuando le dedican un homenaje en un instituto, y reflexiona sobre el carácter infernal de la guerra y la posguerra:

Catalina sintió una enorme tristeza, que venía a sumarse a otras tristezas... Se preguntó una vez más qué habría ocurrido en aquella tierra para que años atrás estallara una guerra que había liberado a todos los demonios, unos demonios que ahora campaban a sus anchas por doquier (41).

Empieza haciendo referencia a las terribles represalias y persecuciones de la primera posguerra, cuando los guardias se llevan a su hermano y a su madre para torturarlos. Meses después vuelven y el hermano tiene que echarse al monte a combatir: “Por qué algunas personas tenían que refugiarse allí y vivir como las alimañas?” (43). Las tristezas se suavizan, sin embargo, con las visitas prohibidas del joven Emilio y sus paseos hacia la que bautizan como "Fuente de los besos". La Catalina anciana del futuro mantiene sus recuerdos intactos, a pesar de haber tenido que huir del pueblo a los dieciséis años y de haberse casado con Lucien con el que tuvo un hijo en Francia.

A diferencia del entorno urbano del Madrid de Cielo abajo, en este caso, se ofrece una perspectiva rural desde la montañosa Asturias, en la postguerra y con el contrapunto actual de la protagonista en su vejez. Su perspectiva femenina en la juventud es menos conocedora de los acontecimientos de la guerra que la del Joaquín de la novela de Marías. Su labor es similar a la del espionaje de aquel pero para el bando contrario; actúa como enlace de los contrafascistas, pero desde la ignorancia y angustiada por un sinfín de dudas terribles sobre la represión: 
-¿Qué cosa mala hemos hecho- le preguntó.

-No hemos hecho nada malo, ni lo hacemos ahora-respondió.

-Entonces, ¿por qué los guardias nos vigilan a todas horas? ¿Por qué mi padre lleva años en la cárcel, si no ha matado ni ha robado a nadie? ¿Por qué mi hermano se ha tenido que echar al monte?

-Porque desde que acabó la guerra, en este país no hay justicia... por eso luchamos nosotros, para que vuelva la justicia (G. Cerdá, 2017, 80).

Por último, esta obra añade dos elementos sociales importantes que no se habían mencionado en la de Fernando Marías. En primer lugar, la persecución de los maestros durante la postguerra; como se puede observar en el siguiente fragmento: “¿Cómo es posible que un maestro se haya tenido que echar también al monte? -Los bárbaros que ganaron la guerra piensan que la cultura y la educación han traído todos los males del país. No quieren hombres inteligentes y libres, les tienen miedo" (141). Un maestro será, además, el que enseñe a leer a Delgadina en el monte. Y, en segundo lugar, el sectarismo de la iglesia católica que apoyaba al bando franquista de los sublevados, e incluso actuaba denunciando a sus feligreses: "Por la mañana habían ido a misa, a pesar de que no eran creyentes, porque sabían que el cura daba a los guardias un papel con los nombre de los que habían faltado, y eso siempre acarreaba complicaciones" (44). Dejamos a la anciana Catalina recordando todos estos terribles aspectos de la guerra durante sus insomnios, que son los que en verdad dan título al libro: Noche de alacranes; porque así es como llama ella a las desagradables noches en que no consigue conciliar el sueño: "Se sentó en la butaca y se dijo que el insomnio, que la noche de alacranes, no iba a angustiarle ni un minuto más. Al contrario, iba a dejarse acunar plácidamente por los recuerdos" (96). Para conocer la historia de por qué los acaba llamando noche de alacranes, la mejor solución será leer la novela, que no se quiere desvelar ahora. En definitiva, se trata de una hermosa historia de amores imposibilitados por los bandos de la guerra, marcados a fuego durante la interminable dictadura. Una aguda perspectiva rural y femenina de esa terrible primera postguerra acompañada por el hambre y la represión franquista.

\subsection{Bajo el fuego de las balas, pensaré en ti, Roberto Santiago y Santiago García Clairac (Barcelona, Edebé, 2014)}

Jaime García Padrino habla en su estudio de esta obra y destaca de ella:

El intento de objetividad por parte de sus autores [...] sin caer en maniqueísmos en la presentación de sus personajes, una familia dividida por su militancia en los dos bandos enfrentados, y desarrollando historias cuyos protagonistas muestran la tragedia del enfrentamiento entre padres, hijos y hermanos, con un cuidado estilo y con el triunfo del amor y de la esperanza por un futuro donde no vuelvan a repetirse tan terribles situaciones (2018, 603).

La temática, pues, está clara, pero, además, nos encontramos con una novela que reúne casi todos los requisitos para agradar a los lectores jóvenes.

Si comenzamos hablando del estilo, como rasgo de la LIJ, encontramos una obra de 311 páginas, dividida en sesenta capítulos y un epílogo cuya extensión es mínima (desde las dos hojas hasta las seis o siete, sin llegar nunca a las diez) y compuesta por frases muy cortas y sencillas (a veces, incluso, excesivamente cortas), con un fuerte componente cinematográfico y visual que hace pensar casi en un guion de cine o de teatro donde el título de cada capítulo, que ofrece las coordenadas espaciotemporales exactas, serviría como acotación para que el lector sitúe la escena que va a presenciar (pues los capítulos son eso: escenas). Esta sensación se agudiza cuando vemos la tabla de personajes que abre el libro y cuando leemos las últimas escenas, pues, si en los primeros capítulos, los autores van cambiando de espacio y tiempo (con juegos de simultaneidades que nos permiten ver qué ocurre al mismo tiempo en lugares diferentes) en los últimos existe linealidad, es decir, entre un capítulo y otro no cambiamos de escena, simplemente se eliden detalles que no aportan demasiado y que podrían ralentizar la narración. Como señalaba, como si de una película se tratase, el cambio de capítulo es el fundido en negro que separa el disparo de la escena en la que aparece la persona herida en el suelo (por poner un ejemplo).

Por otro lado, en la obra aparecen todos los temas que podríamos esperar en una historia de LIJ, señalados por Roig: amor, amistad, misterio..., y asistimos al crecimiento del protagonista, Rodrigo Sandiego, que evoluciona desde un patriotismo vacío hasta el descubrimiento de lo que realmente importa: "en esos momentos, la guerra le daba igual./ [...], de pronto, no era una prioridad. /Ahora solo quería ayudar a su hermana" (204).

Respecto a la temática propia de la LIJ, es interesante observar que no todos los temas giran en torno al protagonista joven, sino que el padre, Florencio Sandiego, también adquiere relevancia. Así, en lo que toca al tema del amor, todo parece indicar que la gran historia es la que sucede entre Rodrigo y Sofía Palacios, que, desde que se conocen en una librería en el Madrid de la inmediata preguerra, se enamoran intensamente y son capaces de superar todos los obstáculos (como el rechazo de la madre de ella por el novio de padres comunistas, la persecución del enamorado rechazado o, incluso, las mentiras sobre Rodrigo que llevarán a la joven a ir a buscarlo al frente). Sin embargo, más allá de esta historia de amor convulsa y adolescente, descubrimos que la frase que da título al libro se refiere a la pareja que forman los padre de Rodrigo: Florencio y Olivia. De su historia se nos van dando pinceladas: se conocen 
en París y ella, de familia falangista, abandona a los suyos para casarse con él, republicano convencido, y luchar a su lado. Cuando la parte de la historia a la que asistimos comienza, Olivia ya está muerta, pues muere en la defensa de los mineros asturianos, pero Floren jamás la olvida: "el amor que aquel hombre seguía sintiendo por Olivia sería capaz de vencer cualquier obstáculo" (310), y, por eso, las últimas frases del libro se les dedican a ellos: "Pero también sabía que, por muchas batallas, muertes y horrores que viviera, incluso bajo el fuego de las balas siempre pensaría en ella. /En el amor de su vida." (311)

Igualmente, si el triángulo amoroso adolescente se establece entre Rodrigo, Sofía y Rubén Gayarre, el verdadero conflicto pasional lo vemos entre el teniente Mueller, su amante, Mariana Monsanto (tía de Rodrigo), y su mujer, Olga Mueller, pues, será en este caso en el que encontremos un desenlace violento cuando el teniente y Mariana se alíen para matar a la esposa.

En lo que respecta a la amistad, también debemos señalar que los ejemplos más claros los encontramos entre los adultos. En este caso, ni siquiera se dice nada de los adolescentes, pero sí vemos cómo Floren y Cambero se ayudan constantemente, cómo Pau se alista voluntario para acompañar a Floren en el campo de batalla y cómo el capitán Andrés Miralles pone balas de fogueo para salvar a Floren del fusilamiento por desertor.

Así pues, es de destacar que en esta obra catalogada como juvenil y que cumple con todos los requisitos para que así sea, también se dedica un espacio importante a los adultos que aparecen como referentes y que, de manera casi paralela viven situaciones semejantes (recordemos que tanto Floren como Rodrigo son considerados traidores por su propio bando y acaban luchando solo por su familia).

En lo que se refiere a otro de los enfoque característicos de la LIJ contemporánea, el feminismo está presente en todo el libro, pues casi todas las mujeres que encontramos en ambos bandos se caracterizan por la fuerza y la determinación. Así, Olivia, la madre de Rodrigo, como ya se dijo, muere defendiendo a los mineros asturianos y Elena, su hija y hermana de Rodrigo, también se alista como miliciana y acaba en el frente junto a otras muchas chicas. En el otro bando, Mariana, tía de Rodrigo, se presenta como una mujer calculadora que, desde la retaguardia, aprovecha su relación con Mueller para mover los hilos y ser ella quien decida, por ejemplo, convertir a su sobrino en espía o mandar la aviación cuando este pide socorro. Por su lado, Sofía, más alejada de lo bélico, abandona su casa para cuidar y proteger a su amado y es capaz de matar para defenderse.

Si pasamos ya al tratamiento del tema de la Guerra Civil española, como señalamos, Jaime García Padrino dice de esta obra que destaca por el "intento de objetividad" en la que los autores evitan "caer en el maniqueísmo" (García Padrino: 2018, 603). En efecto, podemos afirmar que Santiago y García Clairac superan la fase de idealización de los escritores de los años 80 o 90 en los que los personajes resultan "demasiado buenos" y en las que "desde un punto de vista de su eficacia literaria se echa en falta quizá [...] una cierta tensión dialéctica, alguna grieta en el inquebrantable muro de su resistencia moral" (Vilavedra: 2006, 8) y, lejos de una caracterización maniqueísta, la obra habla de los combatientes como "hombres normales" (64) y se inscribe en una ideología antibelicista y antimilitarista, donde queda clara la barbarie y el sinsentido de la guerra, donde todos son capaces de heroicidades para salvar a sus compañeros, pero también de los hechos más atroces, como disparar a sus propios amigos (caso de Floren y Pau), disparar por error a su amada u obedecer órdenes absurdas, como si de máquinas que no piensan se tratasen, para seguir "aquella disciplina mal entendida" que "no era humana" (201); donde "un hombre podía perder la vida por cualquier motivo, o sin él" (201).

Su viejo amigo Pau estaba tendido en el suelo, ensangrentado, delante de él.

Notó que el estómago se le encogía.

Se agarró al estribo y vomitó.

El mundo se le cayó encima. ¡Había matado a sus propios compañeros! (198)

De repente, comprendió que aquello en lo que había creído, aquello por lo que había luchado, había desaparecido en un instante.

$[\ldots]$

Todas sus ideas perdían valor.

La guerra no tenía sentido.

(299)

Cuando Florencio, tendido en una colina, ve cómo cientos de hombres de ambos bandos van muriendo por conseguir una posición, llega a la conclusión determinante que resume la ideología antibelicista de la obra: "Florencio Sandiego se sintió avergonzado de formar parte de aquella guerra. [...] Supo que, fuese cual fuese el resultado final, no habría vencedores. Solo vencidos." (241).

Frente a este sinsentido, se ponderan los valores que realmente importan y por los que merece la pena luchar: la familia, la amistad y el amor:

A partir de ese momento, él no lucharía por su patria.

Ni por unas ideas.

$\mathrm{Ni}$ por el poder. 
Lucharía única y exclusivamente por el amor a su hija.

Una razón mucho más grande que la que pudieran tener todos los generales y políticos juntos.

(156)

Por otro lado, como en otras obras de este tipo, aquí también encontramos hechos históricos mezclados con la ficción. Así, la obra se sitúa en un momento muy concreto, la batalla del Ebro, y se localiza en los diferentes puntos del frente en los que se mezclan los personajes reales con los personajes de ficción. Es curioso ver que, al tratar un hecho conocido con un desenlace sabido por todos, igual que Lope de Vega en el s. XVII, los autores juegan con la complicidad del lector y con el recurso de saber más que los personajes, lo que queda plasmado en una constante repetición de "Sabían que", pero "lo que no sabían era...", como cuando los franquistas abren las presas de Camarasa y Tremp para impedir que los republicanos crucen el río y leemos: "No sabía que esta riada estaba provocando cientos de bajas. No sabía nada de esto. Pero sí sabía que el agua estaba a punto de engullirlos en pocos segundos.” (79).

Por último, teniendo en cuenta lo que tiene que ver con el nacionalismo, podemos decir que se trata de una obra que contempla la Guerra Civil como un mal que aquejó a toda España y, por eso, aparecen muchos lugares diferentes, no solo del frente, sino también Madrid, Barcelona, Logroño, Burgos etc. e incluso tienen presencia los brigadistas que combatieron junto a los republicanos y los alemanes que apoyaron a los generales sublevados.

Como decía, probablemente lo más interesante de este libro es la visión de la guerra como un mal general, donde todos pierden, donde no hay buenos y donde las acciones generosas o heroicas no vienen de los bandos, sino de las personas, que, sin embargo, tampoco son héroes o heroínas sin fisuras sino personas reales que a veces se equivocan o tienen miedo. Se trata de una obra que, probablemente, se acerca más a las visiones de la Guerra que nos han dejado los que la vivieron (Ramón de Valenzuela, Elena Fortún) y en eso radica su principal valor.

\subsection{Un año en el faro, Miren Agur Meabe, (Salamanca, Lóguez, 2008)}

Nos encontramos, esta vez con la historia de Jon Iturri Mendieta, de doce años, que nos cuenta en primera persona su experiencia en el faro de Garraiceta (denominación literaria que la autora da a su pueblo natal, Lekeitio), durante los primeros momentos de la Guerra Civil.

Se trata de una obra en la que queda especialmente claro el foco nacionalista del que venimos hablando. En esta ocasión, solo interesa la casuística vasca y, por ello, parece que la guerra no fuese tanto una contienda que asolase a toda España sino un problema que afectase a los vascos, en especial en lo que se refiere a su autonomía ("¿Qué va a ocurrir ahora con el Estatuto?” $(2008,26)$, pregunta el tío del protagonista al histórico Estepan Urkiaga, intelectual y miembro activo del PNV). Así mismo, la oposición España/Euskadi está presente en toda la obra, como en el momento en el que, en una homilía, se plantea la disyuntiva entre la madre tierra vasca y el toro español que lleva la guerra: "pensad con sosiego dónde ponéis el corazón: si en el seno de la Madre Tierra, bien amada por nuestro Señor, o en el asta del toro que se acerca mugiendo desde esas tierras de España" (20); o, incluso, dentro de las filas del ejército republicano donde, según las cartas del padre del protagonista, se reproduce el mismo enfrentamiento: "Los chicos se han peleado. Es verdad que una cosa es el Ejército de la República y otra el Eusko Gudarostea, que no es lo mismo ser soldado que gudari. Sin embargo, el objetivo es el mismo" (110). De aquí se deduce que, aunque luchen junto al gobierno legítimo de la República que les iba a conceder la autonomía, los gudari no se consideran soldados republicanos. Por otro lado, el sesgo local queda ya claro desde el principio, cuando se dedica la obra "a mi pueblo", y se extiende en las múltiples referencias a la cultura vasca, bien a partir de localismos o palabras en vasco (incluso en la versión castellana de la obra), bien en la aparición de la mitología (las lamias), o en las costumbres populares, coplas, poemas etc. $(76,77)$. El elemento político nacionalista, sin embargo, es mucho más fuerte. En primer lugar, se ve en afirmaciones como la que hemos visto en boca del cura del pueblo (otro de los curas nacionalistas, como los que son fusilados por el bando nacional, en oposición a la Iglesia oficial, 66) u otras en las que queda claro que el "nosotros" no se refiere a los españoles ni a los republicanos, sino solamente a los vascos: "lo más triste de todo es la división entre nosotros. Unos, los simpatizantes del carlismo, ya se han sumado a la rebelión junto a los primeros grupos armados; los otros se han alineado con los republicanos" (27); sobre eso no hay duda, y la única diferencia que se contempla es la de un nacionalismo abierto y acogedor con los "extranjeros" y otro que no lo es: "Euskadi es la patria de los vascos- solía decir mi padre-. Pero si despreciamos a los que vienen aquí a ganarse la vida, nunca se sentirán como uno más entre nosotros" (23). Por otro lado, la obra se erige como homenaje a las figuras fundadoras del PNV y del primer diario escrito en euskera, el Eguna, que es especialmente importante por su vinculación con la defensa de la palabra y de la lengua:

En Euskadi hay una docena de periódicos más o menos, pero éste es el primero que sale entero en euskera. Cuantos más periódicos tengamos, más voces se oirán, pero te digo que éste es el más claro para nosotros, y que nos dará más ánimos. Cuando acabe la guerra, ya estaremos acostumbrados a leer en nuestra lengua (78).

De acuerdo con esto, las referencias a personajes reales de la época son siempre a figuras destacadas del nacionalismo vasco, cuyos datos reales quedan consignados a pie de página: Estepan Urkiaga "Lauaxeta", Eusebio Erkiaga, Bernat Etxepare; Agustín Zubikarai; Joxemari Arizmendi-Arrieta etc. Así pues, el elemento didáctico de la obra no 
está enfocado al conocimiento de los hechos históricos relacionados con la guerra, sino con lo que tiene que ver con el nacionalismo. Ahora bien, desde el reconocimiento a los fundadores del PNV, la propuesta de los protagonistas adultos, es decir, del tío de Jon, que será asesinado por sus ideas nacionalistas, y de su novia, la maestra del pueblo, es la de un nacionalismo laico, feminista y de izquierdas:

Mi tío le lanzó una puya para provocarle:

- ¿Y esos qué? ¿Son de esos ejemplares católicos y apostólicos que se hacen cruces en cuanto oyen a la vez las palabras socialismo y patria? Los nacionalistas sois tan beatos que el corazón se os coloca casi a la derecha. Katalin apoyó a mi tío con vehemencia:

-Y pensáis que nosotras vamos a estorbaros, o que no somos capaces de pensar por nosotras mismas, y nos queréis encerradas en casa y en las sacristías (30).

En relación a otras características de la novela juvenil de temática bélica, hemos de decir que la defensa del pacifismo y el antimilitarismo, en esta obra, no resulta tan clara, pues el sector más activista del nacionalismo dentro de la novela sí justifica la violencia para defender la patria. Frente a esa idea, encontramos la voz de las mujeres que defienden la paz, pero, como decíamos, el mensaje no es tan contundente como en las otras obras que hemos visto.

-No traemos hijos al mundo para verlos morir en vuestras guerras.

-¿Por qué dices vuestras guerras? - se enfadó Estepan-. ¿Es que la patria no es de todos? ¿No es deber de todos defenderla?

Se hizo un silencio. La respuesta a aquella pregunta era un sí del que nadie conocía el precio aún. Estepan siguió reflexionando en voz alta.

-El patriotismo es el huevo de las guerras, según el escritor francés Maupassant. Katalin, ¿qué dices sobre esto?

-Pues mira, también te respondo con una frase de Sorne: "El niño se hará hombre, la semilla se hará planta". A los pequeños hay que enseñarles a amar la libertad y la paz como si fueran una única cosa, y a creer que hombres y mujeres debemos estar unos junto a otros, no unos detrás de otros. (30-31).

Solo al final del libro aparece una defensa de la paz, más en clave personal que como aseveración general, vinculada a la experiencia del horror que ha vivido Jon:

Katalin murió bajo las bombas. [...]

Mirra se había ido, sin destino. [...]

Estepan fue fusilado. [...]

Mi tío, torturado y asesinado. [...]

¿Y yo? Yo me iba al exilio.

(121)

Y que si el patriotismo era el huevo de la guerra, daba al mundo guerras para destruir la libertad y guerras para defenderla. [...] a pesar de todo, yo maldecía la guerra con todo mi ser, aquella guerra y cualquier otra, entonces y siempre (122).

Relacionado con esto, y coincidente, en este caso sí, con otras obras de la temática, la autora no escatima a la hora de mostrar los horrores de la guerra con escenas de batallas, en las que acaban matando a los amigos heridos para acortar la agonía (87) o del tráfico de los enseres de los soldados muertos.

También coincide la autora con el resto de obras a la hora de incidir en la pobreza y falta de medios del ejército republicano, a lo que se alude en más de una ocasión: "nosotros, ¿qué teníamos aparte de buena voluntad? [...] estábamos tan desorientados que nos disparábamos entre nosotros. Un desastre." (70)

La insistencia en la importancia del papel de las mujeres en línea con la ideología feminista que señalaba Valriu en las obras catalanas y que hemos visto también en las otras novelas analizadas, sigue presente en esta novela que, además de ofrecer modelos de mujeres fuertes y activas, como Katalin o la madre de Jon (que consigue reducir sola a los soldados que la tenían retenida en el faro), explica el papel de las mujeres dentro de la contienda:

¿En qué trabajaban las mujeres?

Conducían los transportes. Atendían a los heridos. Reforzaban las barricadas. Organizaban guarderías. Creaban escuelas para los refugiados. Preparaban las municiones en las fábricas de armas. Cosían ropa para los soldados. Limpiaban los cuarteles. Sustituían las vacantes de los talleres. Sacaban adelante a las familias. Y luchaban en la guerra. (72).

$[\ldots]$

Estas otras [mujeres], eran las otras, la resistencia, y no por ser madres, hijas, mujeres, hermanas o novias de nadie, sino porque en su pecho palpitaba un corazón rojo dispuesto a todo. (75). 
Es interesante observar que los temas que suelen enlazar con la LIJ general, como la evolución psicológica del personaje, el amor o la amistad, en esta obra ocupan poco espacio. Es cierto que Jon se enamora, pero no se incide en ello y los párrafos (ni siquiera páginas) en los que se trata el tema son escasos. Lo mismo ocurre con la iniciación sexual, que parece insinuarse en un sueño, pero se corta abruptamente. En cuanto a la amistad, tampoco ocupa un espacio relevante. La obra, dividida en dos partes y veinte capítulos (ocho la primera parte y doce la segunda, en correspondencia con los meses del año y el año completo que se señala en el título), crea secuencias relativamente cortas que se comportan como escenas o cuadros centrados en un hecho o una acción (la aparición de un muerto en el agua, la visita de la madre, la visita a Bilbao...), y, por ello, no queda espacio para profundizar en la psicología del personaje al que, por ello mismo, no vemos crecer o evolucionar, a diferencia de otras obras de tema semejante.

\title{
3. CONCLUSIONES
}

\author{
Tristes guerras \\ si no es amor la empresa. \\ Tristes. Tristes. \\ Tristes armas \\ si no son las palabras... \\ (M. Hernández, Cancionero y romancero de ausencias)
}

Este poema de Miguel Hernández, que subraya la tristeza de las guerras, frente a la importancia del amor y de las palabras, sintetiza probablemente uno de los principales valores transmitidos por la literatura infantil y juvenil de temática bélica, el pacifismo ${ }^{5}$. En casi todas las obras analizadas en este trabajo aparece una intencionalidad didáctica, y, casi siempre, más allá de la información histórica, se pretende transmitir unos valores antimilitaristas y antibelicistas que puedan dar lugar a un mundo mejor. La narrativa que trata el tema de la Guerra Civil española ha ido evolucionando, como recogen los estudios de Vilavedra (2006) y Regueiro (2011), de forma que en las primeras obras, escritas por los que vivieron la contienda, destaca la falta de idealización y de maniqueísmo; el los años ochenta y noventa, se desarrollaba una narrativa que, como en El lápiz del carpintero, de Manuel Rivas, presenta héroes republicanos que casi se convierten en santos laicos (Regueiro: 2003). Mientras que, ya entrado el siglo XXI, se 1lega a una mirada menos maniquea que, si bien recoge la visión de los perdedores, desde una ideología de izquierdas, trata de humanizar a todos los contendientes (tanto eliminando la demonización como la idealización) y ponderar otros principios como el pacifismo, que es el valor fundamental.

Igualmente, desde la visión del siglo XXI, las obras que tratan el tema de la Guerra Civil, y, especialmente aquellas dirigidas a un público joven, enlazan con el feminismo y tratan de visibilizar el papel de las mujeres durante la contienda.

"Republicana, catalanista, feminista, antibellicista i d'esquerres", decía Valriu (317) sobre la novelística catalana y, como ya anticipábamos, el estudio de cuatro obras relevantes escritas en las distintas lenguas del Estado, demuestra que estas características son extrapolables, también en lo que toca a la importancia de la mirada de lo que hoy denominamos autonomías históricas. Así, junto a valores universales como el pacifismo y el feminismo, encontramos la mirada local y nacionalista en obras como la Miren Agur en la que, incluso el afán antibelicista queda en un segundo plano en aras de transmitir el amor a la patria euskara y la adhesión al nacionalismo vasco. Como también intuíamos, esto puede relacionarse con la idea de un estado plural frente a la homogeneización del estado franquista, pero no deja de llamar la atención la utilización de esta pluralidad republicana para acabar transmitiendo una ideología nacionalista que vuelve a restringir la pluralidad.

En cuanto a la técnica, en general, las historias ficticias se intercalan con datos y documentos reales, ya sean fotografías, como en el caso de Santiago y García Clairac ya sean reproducciones de cartas, como en el caso de Miren Agur para dotar de mayor verosimilitud a las obras y para que no se pierda de vista en ningún momento que aquellos hechos tan atroces tuvieron lugar de verdad. Igualmente, en las obras destinadas a lectores juveniles, casi siempre encontramos características generales de la LIJ, aunque, a veces, apenas se desarrollan, tal vez, porque las secuencias cortas que se centran más en los hechos que en la psicología de los personajes.

Es necesario conocer la historia para no repetirla y, como señala Colomer (2009), los valores que plasmamos en la literatura que ofrecemos a nuestros niños y jóvenes son aquellos sobre los que queremos construir la sociedad del futuro. A juzgar por lo que encontramos en estas obras, lo que se busca es una sociedad que no recurra a las armas y en la que se reconozcan las identidades plurales. Desde esta ideología antibelicista y con la perspectiva que ha dado el paso de los años, la Guerra Civil española se ve en la narrativa juvenil como un episodio del que, de un modo u otro, solo quedaron perdedores, pero también se ha utilizado, desde la perspectiva nacionalista, para potenciar las identidades catalana, vasca o gallega frente a los "otros", en este caso, los españoles. Tal vez sea necesario borrar esa oposición entre "yo" y el "otro" para conseguir la paz, no solo en 1936, sino también en 2020. Las obras hablan por sí 
solas, pero también nos queda a los mediadores la responsabilidad de hacer lecturas críticas, donde a partir del juego, del diálogo, del debate o las múltiples actividades que se pueden llevar a cabo en un aula a partir de la lectura de estas obras (escritura creativa, creación de booktrailers, etc $^{6}$.), construyamos una visión crítica que ayude a configurar la nueva ciudadanía de la que habla Jover (2007).

El pacifismo, tanto como ideología colectiva o como convicción individual, hunde sus raíces en el pasado lejano, desde las enseñanzas de Confucio o Lao Tse hasta figuras históricas del carisma de Gandhi, pero siguen siendo indudables en la actualidad los beneficios de la reflexión sobre un valor fundamental que nos aleja de la violencia a través de los textos literarios juveniles.

\section{BIBLIOGRAFÍA}

Agra Pardiñas, María Jesús y B. Roig Rechou (2004): A memoria das guerras na literatura infantil e xuvenil en lingua galega. Antoloxia, Vigo, Edición Xerais de Galicia.

Colomer, Teresa (2009). "La educación literaria", en Lectura y bibliotecas escolares. "Metas educativas 2021 ", C. Armendano e I. Miret (coords.), Madrid, EOI, 71-82.

Etxaniz Erle, X. (2004). "La ideología en la literatura infantil y juvenil” en Cauce, 27, 83-siguientes.

García Padrino, Jaime (2018): Historia crítica de la Literatura Infantil y Juvenil en la España actual (1939-2015), Madrid, Marcial Pons.

Gräfin, I. (2007): “La memoria de la guerra civil española en la literatura infantil y juvenil”, en Stud. Hist, $H^{a}$ contemporánea, 25, 181-190.

Jover, Guadalupe (2007): Un mundo por leer, Barcelona, Octaedro.

Lluch, Gemma (2010): "Las nuevas lecturas deslocalizadas de la escuela", en Las lecturas de los jóvenes. Un nuevo lector para un nuevo siglo, Barcelona, Anthopos, 105-128.

Marcelo Wirnitzer, G. (2007): Traducción de las referencias culturales en la literatura infantil y juvenil, Frankfurt, Peter Lang.

Martín Rogero, Nieves (2008): “Guerra Civil y posguerra en la narrativa escrita en castellano”, en A guerra civil española na narrativa infantil e xuvenil, B. Roig Rechou, P. Lucas Domínguez e I. Soto López, (eds.), Vigo, Xerais, 31-56.

Olaziregi Alustiza, María José (2008): "La Guerra Civil y sus representaciones", en A guerra civil española na narrativa infantil e xuvenil, B. Roig Rechou, P. Lucas Domínguez e I. Soto López, (eds.), Vigo, Xerais, 13-30.

Planes Ferrer, Guida (2011): "La narració de la Guerra Civil espanyola en els àlbums il·lustrats", en Bellaterra Journal of Teaching \& Learning Language \& Literature, 4-4, 32-47.

Regueiro Salgado, Begoña (2003): "Freixanes y Rivas: dos modelos de novela histórica gallega", en Madrygal, Revista de Estudios Gallegos, 107-116.

Regueiro Salgado, Begoña (2011): "La novelística de Ramón de Valenzuela”, en Dos vidas. Un exilio. Ramón de Valenzuela y María Victoria Villaverde, C. Mejía Ruiz (dir.), Madrid, Editorial Complutense, 165-194.

Roig Rechou, Blanca Ana (2008): “A Guerra Civil na narrativa infantil e xuvenil galega: unha temática incompleta”, en A guerra civil española na narrativa infantil e xuvenil, B. Roig Rechou, P. Lucas Domínguez e I. Soto López, (eds.), Vigo, Xerais.

Roig Rechou. Blanca Ana y V. Ruzicka (2011): "La Guerra Civil española en las narraciones infantiles y juveniles. Un proyecto de investigación", en Crítica e investigación en LIJ, Vigo-Braga, ANILIJ y Universidad do Minho.

Valriu Llinàs, Caterina (2018): "La Guerra Civil en la literatura juvenil catalana (1975-2011): tractament i recepció", en Actes AILLC, Tercer volum, 295-313. Http://aillc.espais.iec.cat/files/2018/04/Actes_16_Salamanca_201_295_314. pdf.

Valriu, Caterina (2013): “Guerra Civil i narrativa juvenil catalana: testimoni i literatura”, en Revista de filología románica, 30-2, 309-323.

Vilavedra, Dolores (2006): “A guerra civil na narrativa galega: un ámbito moral”, en Grial, 170, 128-133.

\footnotetext{
El diseño de propuestas concretas para trabajar estas obras en las aulas de Magisterio, de segundo ciclo de Primaria y de Secundaria, desde una perspectiva didáctica y lúdica, a partir de una lectura activa de estas obras, se desarrollará en otro artículo que vendría a completar lo que aquí se ofrece.
} 
